That perspective, announced

Cancel This Book: The Progressive Case Against Cancel Culture, Dan Kovalik, Hot Press, 2021, pp. 199, $\$ 24.99$ hardcover.

\section{A Liberal Takes on the Progressives}

\section{Gorman Beauchamp}

This is an angry book, a righteously angry book, and Dan Kovalik wants to arouse the anger in others, and probably will, although not always in quite the way he would like. His target is that segment of the political left that consider themselves "woke" and who seek to demonstrate that hypersensitivity by exposing those among them who are not-woke (“asnooze”?). This form of exposure they call "canceling" and in its widespread deployment aggregately "the cancel culture." Now both the political left and right have been guilty of canceling and condemning cancelinghypocrisy being nonpartisan-but as a man of the left, and the far left at that, Kovalik wants to make "the progressive case" against this practice. in his subtitle, attracted me to his book. As a man of the left myself, I have always appreciated George Orwell's intense and incisive criticisms of others on his socialist side of the political spectrum: that kind is probably the most telling and truthful. My expectation was that Kovalik, an experienced labor lawyer and peace activist, would offer such kinda of insider analysis, and he does (although I cannot forebear noting that his one reference to Orwell, never in favor with the far left, is jejune and wholly inaccurate). What this analysis reveals, however, is the bifurcation of the left in American politics now. Traditional liberalism, Kovalik's and mine, rests on economic issues and questions of class; the wokies' liberalism focuses on status and questions of identity. The two are not, of course, wholly mutually exclusive, or they would not share the same rubric; but the centers of gravity are distinctly different. On the occasions he adduces some particularly woke absurdity, Kovalik insists that is a left he wants no part of.

An example that he does not cite, but that encapsulates the difference between the two liberalisms

Gorman Beauchamp is the author of a book on Jack London and essays on subjects ranging from Shakespeare to science fiction; gormanb@umich.edu. Beauchamp is also an associate professor emeritus of humanities at the University of Michigan. He last appeared in these pages in the spring of 2021 with his essay "Not Your Father's Campus Anymore." 
concerns the Governor of Virginia, Ralph Northam, whose picture in a 1984 medical yearbook showed him in blackface. This revealed, the woke clamored for his resignation, this single photo from more than thirty years before was sufficient evidence, apparently, of his (presumably still operative) racism. Governor Northam did not resign, polls showed that 60 percent of Virginia's African Americans approved of his decision, and he went on for the rest of his term to do more for black Virginians, it was generally agreed, ${ }^{1}$ than any governor before him. As the head of the Richmond NAACP opined about this controversy, "People can continue to talk about yesterday. I want to talk about tomorrow." Woke sound and fury versus practical political activity, and getting things done.

Kovalik's own test case concerns an eighty-five year old peace activist, Molly Rush-the book is dedicated to her-who reposted a meme on her Facebook page, a picture of Martin Luther King, Jr. with the statement: "Looted nothing. Burned nothing. Attacked no one. Changed the world.” This simple act brought the woke world down on her head: she had thereby-in implicitly criticizing the violence of the Black Lives Matter protests, then the rage-revealed herself to be a virulent racist. Molly, as Kovalik calls her, apologized, repeatedly, for her "error," but the condemnation nevertheless metastasized, growing to include the peace organization-the Thomas Merton Centerthat she had helped to found many years before, but with which she had no recent affiliation. Nevertheless, because she had long been identified with the organization, it too received a barrage of criticism for not having publicly condemned her. (Guilt by association constitutes a common woke tactic.) The Center, knowing which way the wind blows, quickly joined in the chorus of condemnation, issuing a puerile apologia that ought to be read by all to witness the abject depths to which liberal guilt can descend. I recall my amusement in my younger years at certain religious practices that feature adherents parading through the streets lashing their backs with whips or chains, expiating their sins: the Thomas Merton Center provides the contemporary and not at all uncommon equivalent, masochism as policy.

1 That is, if one considers "doing something for black Virginians" to include making Virginia the first state in the South to abolish the death penalty, allocating more than $\$ 300$ million to the state's black colleges, passing sweeping police reform measures, and creating the country's first state cabinet-level position for diversity, equity, and inclusion. See Astead W. Herndon, "Black Virginians Took Ralph Northam Back. Neither Has Forgotten," New York Times, June 21, 2021. 
This first chapter, "Cancellation of a Peace Activist," is the book's longest and demonstrates Kovalik's technique throughout: he examines a hot button topic-the war in Afghanistan, the government's Covid 19 policies, Israel's treatment of the Palestinians, for example-often seeming to forfeit specific focus on the cancel culture, only to show how, ultimately, the two cohere. Here he examines at some length the Black Lives Matter movement with a critical eye, detailing the frequent gap between pronouncement and practice: how the violence in its demonstrations is often perpetrated by young white anarchists intent on causing chaos, how the victims are often small, marginalized business owners, how local black leaders often try to keep the marchers out of their neighborhoods, fearing the consequences. Equally important for Kovalik, the movement has no practical political agenda: This is "not a 'left' that will succeed in creating significant social change.” But anyone who expresses criticism of its motives or methods, or admits reservations about its extremism-"Defund the Police"-runs the very real risk of woke retaliation a la Molly Rush. He has the case histories to prove it.

An important distinction between the old left and the new is revealed by this pile-on rush to judgment, made possible by social media. Among the old left, honor accrued when men went to jail for refusing to name the names of their confederates before congressional committees; among the new left, preeminence goes to those who snitch first and snitch loudest. Let the first sign of woke idee recue deviance appear in the water, and the ideational equivalent of a shark attack occurs. "[M]any seem to see it as a badge of honor to effectively get someone fired, as long as they are fired in the ostensible interest of social justice or antiracism."

What accounts for the prevalence of the woke mob mentality? Kovalik makes no attempt to explain the shift psychologically, but I cannot forebear recommending Greg Lukianoff and Jonathan Haidt's The Coddling of the American Mind (2018), which I do at every opportunity, for its analysis of the infantilizing of America's middle class young, a phenomenon very much contributory to the woke mentality. Kovalik rather sees the bifurcation economically: “In today's discussion about race. . . the entire issue of class-one that could unite workers of all races in a common struggle-is conspicuously missing." Identity politics is the product of bourgeois liberals who have no fiscal skin in the game.

Kovalik's hostility, in fact, seems directed much more at these liberals, 
whom he sees abetting conservative policies, than at conservatives themselves. In a chapter titled "Taking Out the 'White Trash," he excoriates the liberal leadership of the Democratic party for having sold out the economic interests of the white working class for status issues of minorities, with a concomitant increasing contempt for poorly educated Joe Sixpack. (Donald Trump let it be known, by contrast, how he loved poorly educated voters, who, in turn, loved him.) Takes no ghost come from the grave to tell us that the Democratic party has largely lost the white working class; to affect a reconnection between this class and the kind of economic (as distinct from social) policies that would make Democrats a labor-centered party again would necessitate a radical revisioning of how the liberal elite views the man in the street. While one sees the cogency (if, perhaps, the implausibility) of his argument, his resentment of the liberal elite tempts him to simplistic stereotypes. For no reason I can see, he refers to David Remnick of the New Yorker as a "trust fund liberal," in a context where that characterization was completely irrelevant. More significant, he cites four separate times Hillary Clinton's use of "deplorables" to refer to the whole of Trump's electorate: she never did. Her term was "a basket of deplorables" (unfortunately rather precious in itself) and her referent was only the worst elements of his base. If she had in mind the raucous buffoons of the MAGA rallies-“Lock her up"-she was actually guilty of understatement. But throughout the book, Kovalik's animus seems directed more at these liberal types than their conservative counterparts: Maureen Dowd takes it on the chin, Tucker Carlson gets a pat on the back.

All the divergent issues raised in Cancel This Book ałways funnel back into what Kovalik sees as a betrayal of true liberalism. Sometimes it's not that certain ideas get canceled, but that they never get a fair airing in the first place: not like the speaker whose invitation is rescinded because of protests, but one who's never asked for fear of protests. In either event, the principle involved is free speech: "The main problem with 'cancel culture' as I see it is that it suppresses speech and coerces people into staying silent about things that they believe and that others believe, but about which they are afraid to speak." All my life I had adhered to that Voltarian declaration, tacitly endorsed in the First Amendment, and would have cited it as fundamental to liberalism: I may disagree with what you say, but I would defend to the death your right to say it. Or Orwell's more prosaic 
formulation: "Freedom of speech is letting others say what you don't want to hear." This still seems a bedrock belief for liberalism for me. Not for the new breed.

As I was writing this review, I came across a textbook case exemplifying this change. The student president and a couple of others at the University of Connecticut began adapting for their institution a version of the Chicago Statement, which emphasizes the importance of free speech on college campuses. Even before they had finished, the attacks began: "It went very negative, very quickly." "Free speech," went the charge, was just an excuse for "hate speech": a policy endorsing open dialogue was an invitation to bigotry. A radical subgroup had commandeered the whole narrative of free speech, the UConn student president felt, and the majority of students who supported a statement of civil liberties were wary of doing so publicly for fear of being labeled bigots. This dynamic, unfortunately, prevails at many campuses today, in even more egregious manifestationsexpulsions, firings, censure of staff and students. Kovalik's chapter "Witch Hunt in the Academy" offers a plentitude of depressing, outrageous, but only too familiar examples, most taken apparently from a National Association of Scholars site where even more are documented. ${ }^{2}$

A shocking feature of this sottisier is how minor, how incidental, how even erroneous the perceived breaches often are: who can forget the Washington bureaucrat reprimanded, then fired for using the word niggardly about budget provisions? Students urged the firing of one UCLA professor for his reading aloud King's “Letter from a Birmingham Jail” the way King wrote it, including the word nigger. Scanning the 178 such cases (to date) on the NAS site, one must be awestruck by the sheer inanity rife there. What's going on?

Of course, ours has become the age of grievance collectors, identity mavens relishing all the microaggressions they can uncover or invent, stumbling over each other to be the first to find what the ideologically less perceptive would have missed and get someone fired. Let me be frank: I think, for all practical purposes, they are stupid. To paraphrase the letter gulling Malvolio in Twelfth Night: some people are born stupid, some achieve stupidity, and some have stupidity thrust upon them. To the degree that such word police are acting on sincere

2 "Tracking Cancel Culture in Higher Education," National Association of Scholars, https://www.nas.org/ blogs/article/tracking-cancel-culture-in-higher-education\#caseslist. 
belief-as opposed just to posing for the camera-the quality of mind involved resembles those best off on lithium. Many probably fall into the second category, those who achieve stupidity-in school-a learned ideological stupidity. But probably the majority, one hopes, belong to the third category, those who have stupidity thrust upon them: not true believers themselves in these absurd sorts of charges, but out of inertia and fear of being canceled themselves they remain silent and thus complicit. The very best that can be said for the college administrators who, if not initiating, implement the various punishments is that they are self-protecting cowards; any other conclusions are too depressing to contemplate. Apropos Kovalik quotes lines from Yeats's "Second Coming”: “The best lack all conviction, while the worst/ Are full of passionate intensity.”

His deepest regret seems to be that the battles that the young left used to fight have been abandoned for gestural, feel-good causes: "I suspect that a significant reason why many people have stopped fighting for real change-peace, healthcare for all, a better standard of living for workersand instead have limited themselves to the symbolic battles of fighting over the use of language and which statues should be allowed to stand is that they feel they have a much better chance of winning the purely symbolic battles." The issues the young radicals of the 1960s and 70s rallied and marched over

seemed like issues worth fighting about. It would never have occurred to us to expend energy trying to take someone's livelihood, especially for the type of minor infractions people are canceled for today. . . . As Marxist Adam Lehrer puts it very well, "[c]ulture war is merely the illusion of politics; it's what remains when hope for real change has died." In other words, it is the politics of despair.

On this ground depends the "progressive" dimension of Kovalik's case against the cancel culture-what sets it apart from other critiques which have other agendas: he laments the squandering and misdirection of the radical left energy that could better be directed to solving real-that is, economic-problems. He extends his critique by noting that the nitpicking, character assassinating nature of cancel culture politics makes common cause with other political forces all the more difficult; like the identity groups that it mirrors, it divides rather than unites. I 
opened by characterizing Cancel This Book as a righteously angry book, righteous because I share his view of the cancel culture. But is it the kind of book that would ever convince many of its subjects to grow up and get real in what political objectives they ought to be following? Would they want to concern themselves with child poverty in Appalachia when the cafeteria at Oberlin needs censuring for the inauthentic nature of its ethnic cuisine or Caucasian girls are wearing cheongsams to proms unrebuked? 